\title{
Clinicalpathological and prognostic significance of survivin expression in renal cell carcinoma: a meta-analysis
}

\author{
Zhichen Pu ${ }^{1,2, *}$, Guang-Zhen Wu ${ }^{1, *}$, QiFei Wang ${ }^{1}$ \\ ${ }^{1}$ Department of Urology, The First Affiliated Hospital of Dalian Medical University, Dalian, Liaoning 116011, China \\ ${ }^{2}$ State Key Laboratory of Natural Medicines, Key Lab of Drug Metabolism and Pharmacokinetics, China Pharmaceutical \\ University, Nanjing 210009, China \\ *These authors have contributed equally to this work \\ Correspondence to: QiFei Wang, email: frog080619@163.com
}

Keywords: survivin, renal cell carcinoma, meta-analysis, prognosis

Received: August 19, $2016 \quad$ Accepted: November 07, 2016

Published: February 04, 2017

\section{ABSTRACT}

Background: In recent years, survivin expression had been investigated as a prognostic biomarker for renal cell carcinoma (RCC), however, the results were conflicting. This study was aimed to explore the association between survivin expression and clinicalpathological features and the prognostic value for cancerspecific survival (CSS) and overall survival (OS) in RCC.

Results: Eleven studies with 1,697 subjects were included in this meta-analysis. The results showed that survivin expression was associated with higher tumor grade (OR=4.25, 95\%CI: 3.04-5.95, $\mathrm{p}<0.001)$, advanced tumor stage (OR=3.83, 95\%CI: 2.01-7.3, $\mathrm{p}<0.001$ ) and lymph node metastasis (OR=4.19, 95\%CI: 2.34-7.52, p $<0.001$ ), but had no association with age, gender or distant metastasis. In addition, survivin expression was also correlated with poor CSS (HR=2.08, 95\%CI: 1.07-4.05, $\mathrm{p}=0.032)$ and poor OS $(\mathrm{HR}=2.28,95 \% \mathrm{CI}: 1.57-3.33, \mathrm{p}<0.001)$.

Materials and Methods: Literature was searched by PubMed, Embase and Web of Science. Hazard ratios (HRs) and $95 \%$ confidence intervals (95\% CIs) were extracted from eligible studies. Fixed or random effects model were used to calculate pooled HRs and $95 \%$ CIs according to heterogeneity.

Conclusions: This study demonstrated that survivin expression was associated with more aggressive clinical features and predicted poor CSS and OS in patients with RCC.

\section{INTRODUCTION}

Renal cell carcinoma (RCC) accounts for over $90 \%$ of kidney carcinomas [1]. RCC ranks the seventh and the ninth most prevalent cancer type in men and women, respectively [2]. In 2016, there were estimated 62,700 new cases and 14,240 deaths from RCC in the US [3]. Multiple treatment methods have been applied to treat localized RCC, among which, surgery is the most effective while chemotherapy and radiotherapy have moderate effects. However, approximately 20$30 \%$ of all RCC patients are in metastatic RCC (mRCC) state when diagnosed, what is worse, another $20 \%$ of patients with localized RCC who receiving surgical resection will have a relapse and progress to $\mathrm{mRCC}$ in several years [4]. Unfortunately, $\mathrm{mRCC}$ is one of the most treatment-resistant malignant tumors. Therefore, reliable and novel prognostic biomarkers are important to distinguish high risk patients and to improve clinical outcomes of RCC.

Resisting apoptosis is an important feature of cancer, which confers cancer cells the ability to avoid death on various physiologic stresses [5]. Survivin, containing 142 amino acid residues, is a member of the inhibitor of apoptosis (IAP) family proteins [6]. Accumulating evidence showed that survivin counteracted a variety of mediators of apoptosis to block cell death both in vitro and in vivo [7]. This process in turn facilitates cell proliferation and renders tumor cells resistant to different treatment methods [8]. Survivin was 
proposed as a promising cancer biomarker [9]. Previous studies have shown that survivin expression predict prognosis in various multiple cancer types including breast cancer [10], gastric cancer [11], colorectal cancer [12] and bladder cancer [13]. A variety of studies have investigated prognostic role of survivin expression in RCC, however, the results were conflicting [14-24]. Therefore, it is necessary to carry out a comprehensive analysis by pooling published data.

In this study, we retrieved relevant literature and extracted data from eligible articles to perform a metaanalysis. We aimed to systematically evaluate the clinicalpathological and prognostic value of survivin expression in patients with RCC.

\section{RESULTS}

\section{Features of included studies}

A total of 202 studies were identified through systematic literature searching. After title and/or abstract screening, 22 full-text articles were evaluated for eligibility. Then, 11 articles were excluded for: 2 papers were duplicate studies, 1 paper was a comment and 8 studies lacked key information. At last, 11 studies [14-24] published from 2007 to 2015 with 1,697 patients were included in meta-analysis. The literature selection process was shown in Figure 1. All studies were retrospective study design and detected survivin expression using IHC. Five studies [14, 18, 21, 23, 24] were from Asian countries and six studies [15-17, 19, 20, 22] were from western countries. The sample size ranged from 42 to 634 . The basic features of these studies were shown in Table 1 .

\section{Clinicopathological parameters and survivin expression}

To disclose the significance of survivin in pathological diagnosis, we explored the correlation between survivin expression and clinicopathological characteristics. Data of tumor grade, tumor stage, age, gender, lymph node metastasis and distant metastasis

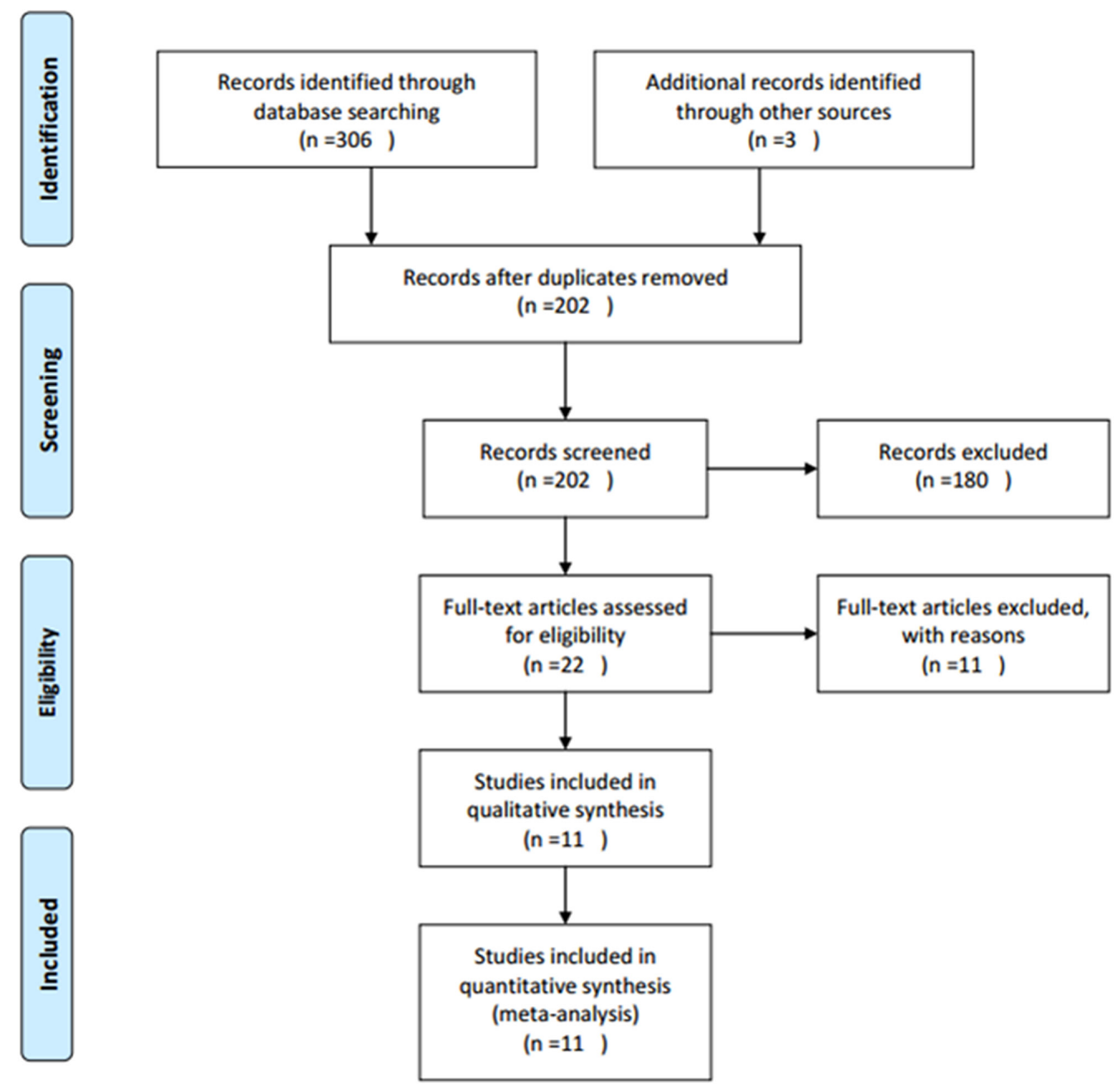

Figure 1: Flow diagram showing process of literature search. 
Table 1: Basic characteristics of included studies

\begin{tabular}{|c|c|c|c|c|c|c|c|c|c|c|}
\hline Study & Year & Country & Ethnicity & Cases & $\begin{array}{c}\text { Gender } \\
(\mathrm{M} / \mathrm{F})\end{array}$ & Method & $\begin{array}{c}\text { Cut-off } \\
\text { level }\end{array}$ & $\begin{array}{c}\text { Survivin }(+) \\
\text { N(\%) }\end{array}$ & $\begin{array}{c}\text { Histological } \\
\text { type }\end{array}$ & $\begin{array}{l}\text { Survival } \\
\text { analysis }\end{array}$ \\
\hline Byun & 2007 & Korea & Asian & 85 & $63 / 22$ & $\mathrm{IHC}$ & $\begin{array}{c}>10 \% \\
\text { staining }\end{array}$ & $67(79)$ & $\mathrm{RCC}$ & OS, RFS \\
\hline Parker & 2008 & USA & Caucasian & 310 & $185 / 125$ & IHC & $\begin{array}{c}>2 \% \\
\text { staining }\end{array}$ & $105(33.9)$ & ccRCC & CSS \\
\hline Zamparese & 2008 & Italy & Caucasian & 49 & $37 / 12$ & IHC & $\begin{array}{c}>5 \% \\
\text { staining }\end{array}$ & $40(81.6)$ & $\mathrm{RCC}$ & CSS \\
\hline Parker & 2009 & USA & Caucasian & 634 & $413 / 221$ & $\mathrm{IHC}$ & $\begin{array}{l}>15 \% \\
\text { staining }\end{array}$ & NA & $\mathrm{RCC}$ & CSS \\
\hline Lei & 2010 & China & Asian & 75 & $36 / 39$ & $\mathrm{IHC}$ & $\begin{array}{c}>10 \% \\
\text { staining }\end{array}$ & $40(53.3)$ & $\mathrm{RCC}$ & OS \\
\hline Baytekin & 2011 & Turkey & Caucasian & 104 & NA & $\mathrm{IHC}$ & $\begin{array}{c}>5 \% \\
\text { staining }\end{array}$ & $24(23.1)$ & $\mathrm{RCC}$ & CSS \\
\hline Dornbusch & 2013 & Germany & Caucasian & 42 & $29 / 13$ & $\mathrm{IHC}$ & NA & $20(47.6)$ & $\mathrm{mRCC}$ & OS \\
\hline Liu & 2014 & China & Asian & 90 & $52 / 38$ & $\mathrm{IHC}$ & $\begin{array}{c}>20 \% \\
\text { staining }\end{array}$ & $74(82.2)$ & ccRCC & CSS \\
\hline Weber & 2014 & Germany & Caucasian & 145 & $88 / 57$ & $\mathrm{IHC}$ & NA & NA & $\mathrm{ccRCC}$ & $\mathrm{CSS}$ \\
\hline Lu & 2015 & China & Asian & 98 & $63 / 35$ & $\mathrm{IHC}$ & $\begin{array}{c}>10 \% \\
\text { staining }\end{array}$ & $51(52)$ & ccRCC & OS \\
\hline Shi & 2015 & China & Asian & 65 & $37 / 28$ & $\mathrm{IHC}$ & $\begin{array}{c}>5 \% \\
\text { staining }\end{array}$ & $47(72.3)$ & ccRCC & OS \\
\hline
\end{tabular}

IHC: immunohistochemistry; NA: not available; RCC: renal cell carcinoma; ccRCC: clear cell renal cell carcinoma; mRCC: metastatic renal cell carcinoma; OS: overall survival; CSS: cancer-specific survival; RFS: recurrence-free survival.

were extracted and then pooled OR and 95\% CI were computed. As shown in Figure 2, tumor grade $(\mathrm{G} 3+\mathrm{G} 4$, $+)$ was associated with survivin expression $(n=8$, $\mathrm{OR}=4.25,95 \% \mathrm{CI}: 3.04-5.95, \mathrm{p}<0.001)$ in fixed-effects model analysis. Furthermore, there were association between tumor stage $(\mathrm{III}+\mathrm{IV},+)(\mathrm{n}=8, \mathrm{OR}=3.83,95 \% \mathrm{CI}$ : $\left.2.01-7.3, \mathrm{p}<0.001 ; \mathrm{I}^{2}=60.2 \%, \mathrm{P}_{\text {heterogeneity }}=0.014\right)$, lymph node metastasis $(\mathrm{yes},+)(\mathrm{n}=5, \mathrm{OR}=4.19,95 \% \mathrm{CI}: 2.34$ 7.52, $\left.\mathrm{p}<0.001 ; \mathrm{I}^{2}=0, \mathrm{P}_{\text {heterogeneity }}=0.851\right)$ and survivin expression. However, survivin expression had no association with age $(n=5, O R=1.22,95 \% C I$ : 0.86 $1.74, \mathrm{p}=0.271)$, gender $(\mathrm{n}=5, \mathrm{OR}=0.8,95 \% \mathrm{CI}$ : 0.56 $1.15, \mathrm{p}=0.224)$ or distant metastasis $(\mathrm{n}=3, \mathrm{OR}=1.22$, 95\%CI: $0.37-4, p=0.748)$. Taken together, the results demonstrated survivin expression in RCC patients could be considered as a significant biomarker for diagnosis of patients with higher grade, advanced stage and lymph node metastasis.

\section{Prognostic value of survivin expression for CSS and $\mathrm{OS}$}

To further estimate the association between survivin expression and prognosis for CSS and OS in RCC patients, combined HRs and 95\%CIs were calculated. As shown in Table 2 and Figure 3, survivin expression was associated with poor CSS according to pooled data $(n=6, H R=2.08,95 \% C I$ : $1.07-4.05$, $\mathrm{p}=0.032 ; \mathrm{I}^{2}=95.1 \%, \mathrm{P}_{\text {heterogeneity }}<0.001$, Table 2, Figure 3). Subgroup analysis indicated that survivin expression had no association with Caucasian patients, in RCC or in clear cell renal cell carcinoma (ccRCC) histological type (Table 2). Meanwhile, survivin expression was shown to be related with poor OS generally and the HR was 2.28 with $95 \% \mathrm{CI}: 1.57-3.33, \mathrm{p}<0.001$, in addition, there was no heterogeneity $\left(\mathrm{I}^{2}=0, \mathrm{P}_{\text {heterogeneity }}=0.498\right)$. Through subgroup analysis, the results showed that survivin expression still had association with Asian patients $(n=5, H R=2.57,95 \% C I: 1.63-4.07, p<0.001)$, in $\mathrm{RCC}(\mathrm{n}=2, \mathrm{HR}=2.15,95 \% \mathrm{CI}: 1.11-4.16, \mathrm{p}=0.023)$ and in $\operatorname{ccRCC}(\mathrm{n}=2, \mathrm{HR}=3.04,95 \% \mathrm{CI}: 1.61-5.76$, $\mathrm{p}=0.001)$.

\section{Publication bias}

Funnel plots for meta-analysis of survivin expression and clinical features as well as CSS and OS were shown in Figure 4. The funnel plots for all analysis 
were symmetric, indicating no obvious publication bias (Begg's $p$ : tumor grade: $p=0.711$; tumor stage: $p=0.266$; age: $p=0.221$; gender: $p=0.221$; lymph node metastasis: $\mathrm{p}=0.462$; distant metastasis: $\mathrm{p}=1 ; \mathrm{CSS}: \mathrm{p}=0.851$; OS: $\mathrm{p}=1$; Figure 4).

\section{DISCUSSION}

Survivin has the ability to inhibit apoptosis and it is also needed for cell division [25]. In several animal models, downregulation of survivin was shown to suppress tumor growth and survivin was validated as a cancer therapeutic target $[6,26]$. In recent years, emerging data suggested that survivin expression can serve as a promising biomarker for prognostication in various tumors, including RCC [15-17, 23, 24]. The conflicting results from different research groups promote us to perform this meta-analysis. In the present study, based on results form 11 studies with 1,697 subjects, the data showed that survivin expression was associated with

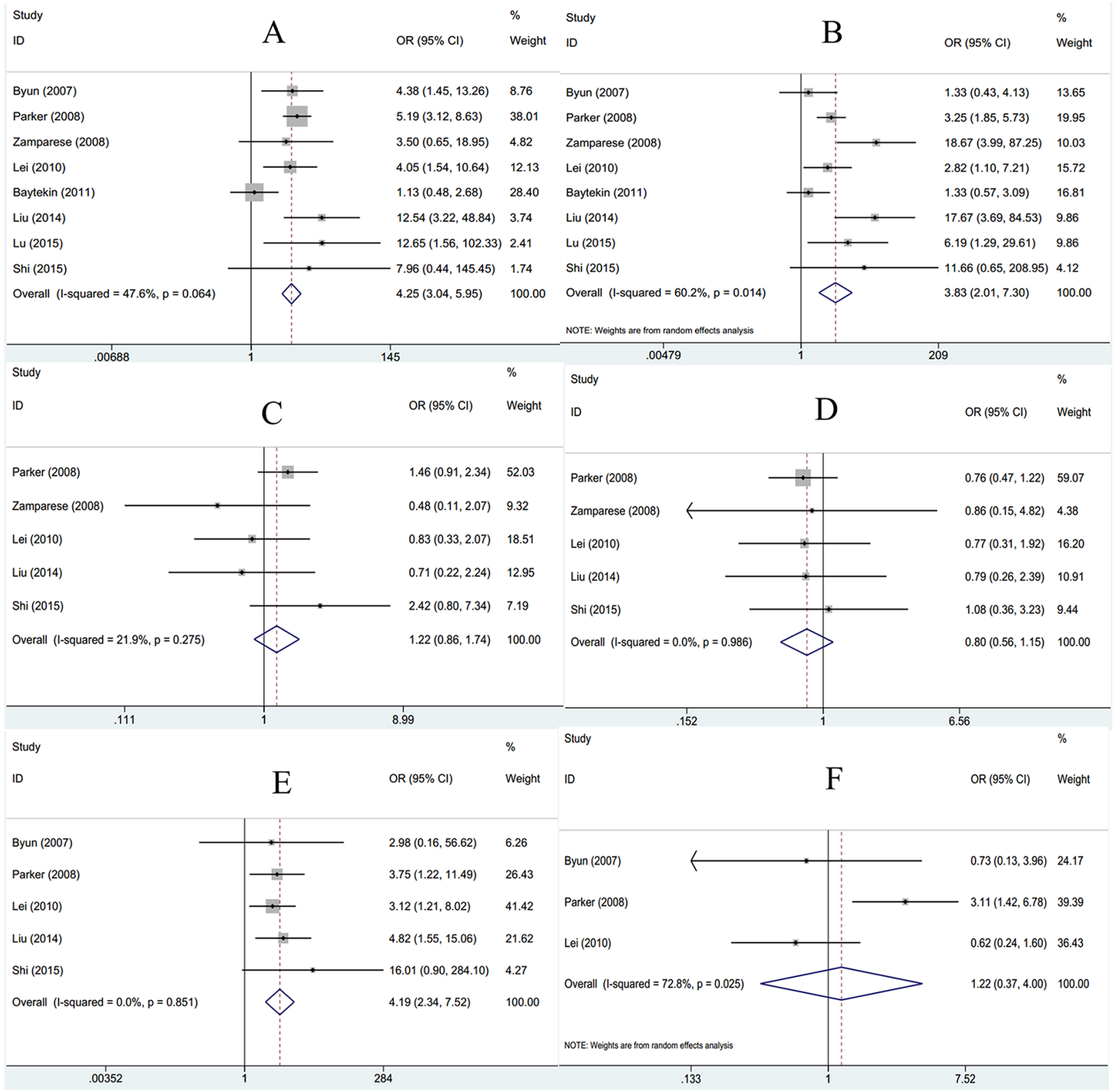

Figure 2: Association between survivin expression and A. tumor grade; B. tumor stage; C. age; D. gender; E. lymph node metastasis and $\mathbf{F}$. distant metastasis in RCC. 
Table 2: Pooled HRs and 95\% CIs in meta-analysis for CSS and OS

\begin{tabular}{|c|c|c|c|c|c|c|c|}
\hline \multirow[t]{2}{*}{ Variable } & \multirow{2}{*}{$\begin{array}{c}\text { Studies } \\
\text { (n) }\end{array}$} & \multicolumn{2}{|c|}{ Heterogeneity } & \multirow[t]{2}{*}{ HR } & \multirow[t]{2}{*}{$95 \% \mathrm{CI}$} & \multirow[t]{2}{*}{$\mathbf{p}$} & \multirow[t]{2}{*}{ Effects model } \\
\hline & & $I^{2}(\%)$ & $\mathbf{P}_{\text {heterogeneity }}$ & & & & \\
\hline \multicolumn{8}{|l|}{ CSS } \\
\hline Overall & 6 & 95.1 & $<0.001$ & 2.08 & $1.07-4.05$ & 0.032 & Random \\
\hline \multicolumn{8}{|c|}{ Subgroup1:ethnicity } \\
\hline Caucasian & 5 & 95.7 & $<0.001$ & 1.99 & $0.94-4.23$ & 0.072 & Random \\
\hline Asian & 1 & - & - & 2.56 & $1.38-4.75$ & 0.003 & - \\
\hline \multicolumn{8}{|c|}{ Subgroup2: histology } \\
\hline RCC & 3 & 82.9 & 0.003 & 1.78 & $0.72-4.43$ & 0.214 & Random \\
\hline ccRCC & 3 & 97 & $<0.001$ & 2.36 & $0.75-7.44$ & 0.142 & Random \\
\hline \multicolumn{8}{|l|}{ OS } \\
\hline Overall & 5 & 0 & 0.498 & 2.28 & $1.57-3.33$ & $<0.001$ & Fixed \\
\hline \multicolumn{8}{|c|}{ Subgroup1:ethnicity } \\
\hline Caucasian & 1 & - & - & 1.78 & $0.92-3.45$ & 0.086 & - \\
\hline Asian & 4 & 0 & 0.463 & 2.57 & $1.63-4.07$ & $<0.001$ & Fixed \\
\hline \multicolumn{8}{|c|}{ Subgroup2: histology } \\
\hline RCC & 2 & 22 & 0.258 & 2.15 & $1.11-4.16$ & 0.023 & Fixed \\
\hline ccRCC & 2 & 0 & 0.39 & 3.04 & $1.61-5.76$ & 0.001 & Fixed \\
\hline mRCC & 1 & - & - & 1.78 & $0.92-3.45$ & 0.086 & - \\
\hline
\end{tabular}

higher tumor grade, advanced tumor stage and lymph node metastasis. Moreover, the results for prognosis analysis also indicated that survivin expression was a predictor for shortened CSS and OS. These results suggested that survivin detection was feasible for tumor aggressiveness evaluation and tumor staging. Survivin could be recommended as a valuable risk factor for RCC diagnosis and prognosis. To our knowledge, this is the first study investigating the prognostic role of survivin for RCC patients by the analytic approach of meta-analysis.

Survivin is a structurally unique member of IAP family. Survivin has been found to suppress apoptosis via inactivation of caspases [27]. Besides apoptosis, survivin also takes part in other physiological procedures such as cellular stress response as well as surveillance checkpoints $[28,29]$. Survivin is highly expressed in fetal tissues and in various human solid tumors. Its multiple functions could facilitate tumor growth and progression in different aspects. Survivin can mediate mitotic progression so as to promote cell division [30]. In addition, survivin is also involved in angiogenesis and its expression is upregulated when exposed to culture with angiogenic factors such as VEGF [31]. This may explain the positive correlation between survivin expression and lymph node metastasis in this meta-analysis. Taken together, current evidence suggests that survivin plays a pivotal role in cancer formation and progression.

The results in the present meta-analysis demonstrated that survivin was a predictor for poor prognosis in RCC, which was in line with conclusions from other solid and hematological cancer types including breast cancer [10], non-Hodgkin's lymphoma [32], nonsmall cell lung cancer [33], glioma [34] and gastric cancer [35]. In addition, we also analyzed the association between survivin expression and clinical factors in RCC and we found that survivin had positive relationship with higher tumor grade and tumor stage. These risk factors are well established in clinical practice and are often used to aid therapeutic regimen selection. The correlation between survivin and the factors revealed that survivin had potential to be adopted as a dichotomous biomarker. The present study is the first meta-analysis systematically evaluating the prognostic value of survivin expression in $\mathrm{RCC}$ to date.

Several limitations need to be addressed. First, significant heterogeneity was detected for several parameters, although we picked random-effect model or fixed-effect model according to heterogeneity, it still 


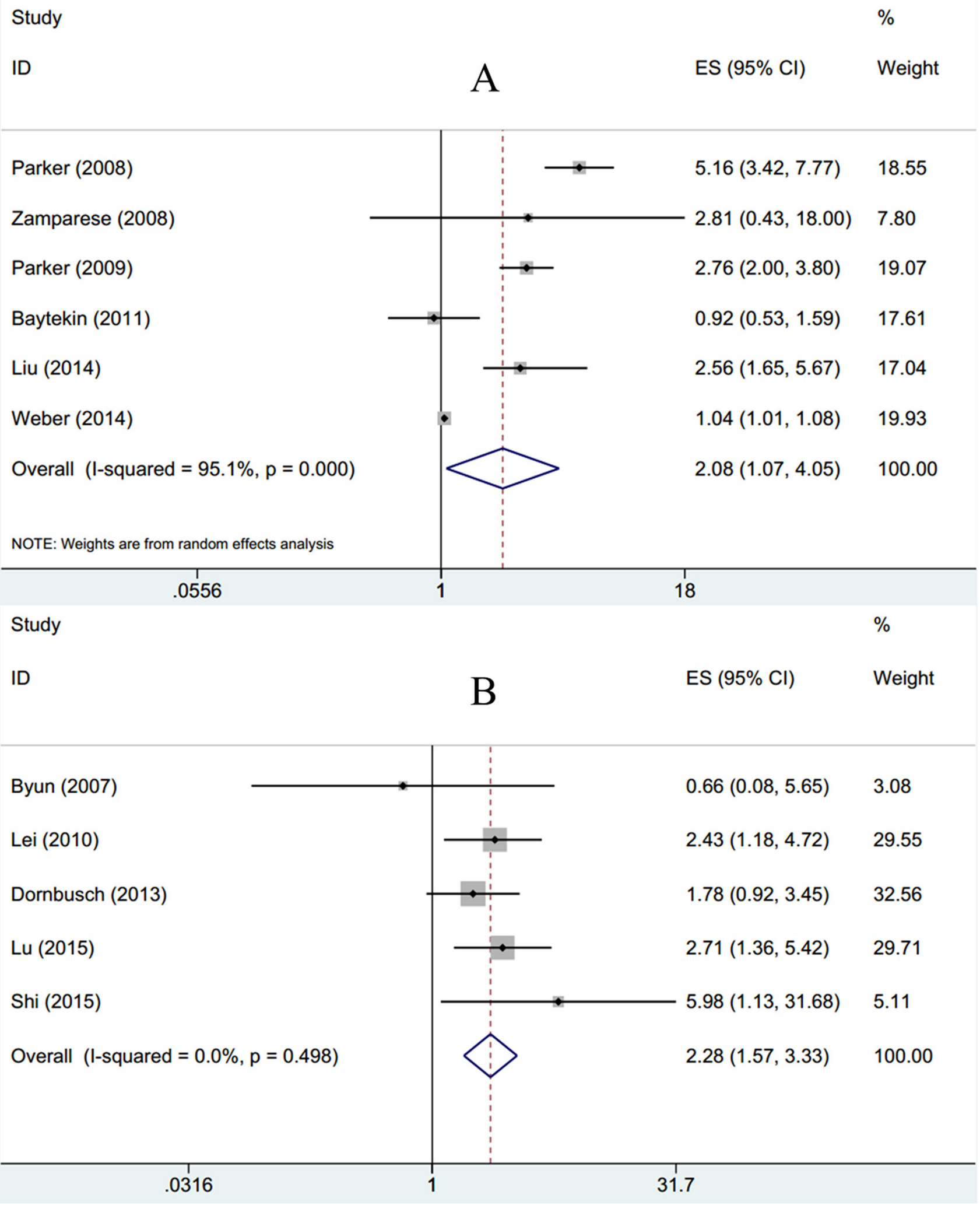

Figure 3: Forest plots to assess effect of survivin on A. CSS and B. OS in RCC. 

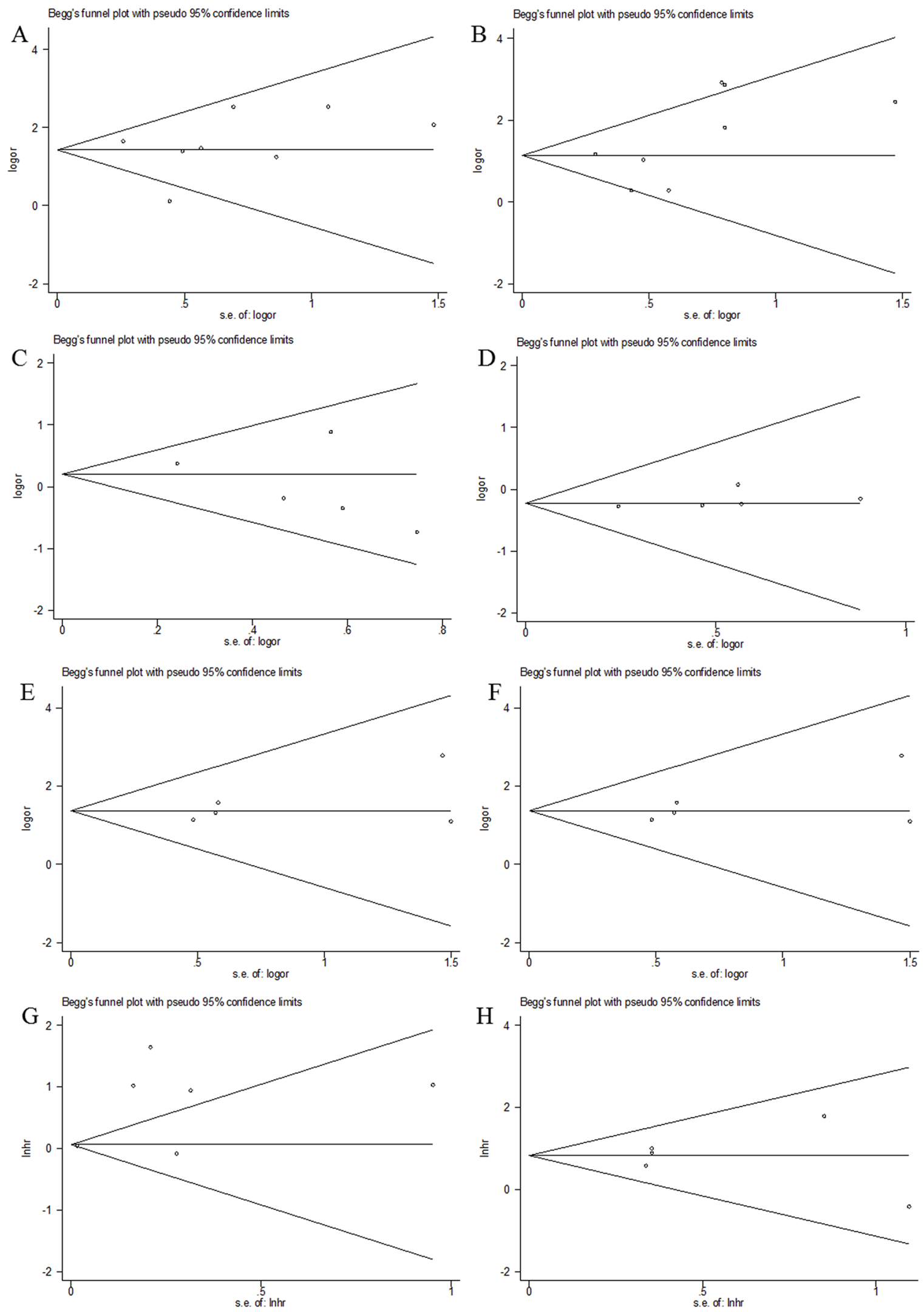

Figure 4: Funnel plots evaluating possible publication bias for A. tumor grade; B. tumor stage; C. age; D. gender; E. lymph node metastasis; F. distant metastasis; G. CSS and H. OS. 
existed due to the difference in included studies. Second, the scale of RCC patients was relatively small; therefore, large scale studies are needed to conceive more reliable results. Third, subgroup analyses for Asian patients in CSS and Caucasian patients and $\mathrm{mRCC}$ in OS were not actually conducted because only one study was included in each of these groups. Thus the results concerning these subgroup patients need to be completed in further studies.

In conclusion, this meta-analysis showed that survivin expression was associated with more aggressive clinical features and predicted poor CSS and OS in patients with RCC. Due to limitations in this study, large scale studies with more complete patients' types are needed to verify our results.

\section{MATERIALS AND METHODS}

\section{Literature search}

A comprehensive literature search was conducted in platforms of PubMed, Embase and Web of Science. The last search was performed on April 2016. The $\mathrm{MeSH}$ terms and free words adopted were as follows: "survivin", "baculoviral inhibitor of apoptosis repeat containing 5", "BIRC5", "renal cancer", "kidney cancer", "renal carcinoma" and "renal cell carcinoma" and their combinations. The reference lists of previous relevant reviews were also manually checked to find additional publications of interest. The language of publications was restrained to English.

\section{Inclusion and exclusion criteria}

The following inclusion criteria were used to select eligible studies: (i) the diagnosis of RCC was pathologically confirmed; (ii) the prognostic value of survivin expression for overall survival (OS), cancerspecific survival (CSS) and/or recurrence-free survival (RFS) were reported; (iii) the expression of survivin was tested by immunohistochemistry (IHC) method; (iv) hazard ratios (HRs) and their 95\% confidence intervals (95\% CIs) for survival analysis were reported in text or could be computed from given data; (v) if more than one articles from one patients cohort were identified, the most complete one was selected. The exclusion criteria were: (i) abstract, review, case report or comment letter; (ii) animal studies; (iii) duplicate publications; (iv) published not in English.

\section{Data extraction}

Two independent reviewers using a standardized form extracted relevant data from eligible studies. The needed information was: first author's name, year of publication, origin country of the study, cases, cut-off levels, histology and survival end point. Discrepancies were discussed until reaching a consensus.

\section{Statistical analysis}

Data were analyzed by using Stata 12.0 (StataCorp LP, College Station, TX, USA). Odds ratio (OR) and 95\% CI were used to present the associations between clinical factors and survivin expression. Hazard ratio (HR) with a 95\% confidence interval was computed to reveal the correlation between survivin expression and prognosis (CSS and OS). If statistical variables were reported in text, then we extracted them directly, otherwise, data was calculated according to the method provided by Tierney [36]. Heterogeneity among studies was examined using Chi-square based Q test in which $\mathrm{I}^{2}$ indicates level of heterogeneity. $\mathrm{I}^{2}<50 \%$ or $\mathrm{P}_{\text {heterogeneity }}>0.1$ represents low heterogeneity, in this case, a fixed effects model (Mantel-Haenszel method) was used, otherwise, a random effects model (Der Simonian and Laird method) was picked. Subgroup analysis was performed for CSS and OS analysis. Publication bias was examined by using Begg's funnel plot. $\mathrm{P}<0.05$ was considered as statistically significant.

\section{CONFLICTS OF INTEREST}

The authors declare that they have no competing interests.

\section{REFERENCES}

1. Chow WH, Dong LM and Devesa SS. Epidemiology and risk factors for kidney cancer. Nat Rev Urol. 2010; 7:245-257.

2. Gupta K, Miller JD, Li JZ, Russell MW and Charbonneau C. Epidemiologic and socioeconomic burden of metastatic renal cell carcinoma (mRCC): a literature review. Cancer Treat Rev. 2008; 34:193-205.

3. Siegel RL, Miller KD and Jemal A. Cancer statistics, 2016. CA Cancer J Clin. 2016; 66:7-30.

4. Athar $U$ and Gentile TC. Treatment options for metastatic renal cell carcinoma: a review. Can J Urol. 2008; 15:3954-3966.

5. Hanahan D and Weinberg RA. Hallmarks of cancer: the next generation. Cell. 2011; 144:646-674.

6. Ryan BM, O'Donovan N and Duffy MJ. Survivin: A new target for anti-cancer therapy. Cancer Treat Rev. 2009; 35:553-562.

7. Pennati M, Folini M and Zaffaroni N. Targeting survivin in cancer therapy. Expert Opin Ther Targets. 2008; 12:463-476.

8. Dean EJ, Ranson M, Blackhall F, Holt SV and Dive C. Novel therapeutic targets in lung cancer: Inhibitor of apoptosis proteins from laboratory to clinic. Cancer Treat Rev. 2007; 33:203-212.

9. Duffy MJ, O'Donovan N, Brennan DJ, Gallagher WM and Ryan BM. Survivin: a promising tumor biomarker. Cancer Lett. 2007; 249:49-60. 
10. Li YY, Ma XL, Wu X, Liu XX and Liu L. Prognostic Significance of Survivin in Breast Cancer: Meta-analysis. Breast J. 2014; 20:514-524.

11. Liu JL, Gao W, Kang QM, Zhang XJ and Yang SG. Prognostic Value of Survivin in Patients with Gastric Cancer: A Systematic Review with Meta-Analysis. PLoS One. 2013; 8.

12. Huang YJ, Qi WX, He AN, Sun YJ, Shen Z and Yao Y. The Prognostic Value of Survivin Expression in Patients with Colorectal Carcinoma: A Meta-analysis. Jpn J Clin Oncol. 2013; 43:988-995.

13. Lv SZ, Turlova E, Zhao SG, Kang HH, Han MZ and Sun HS. Prognostic and clinicopathological significance of survivin expression in bladder cancer patients: a metaanalysis. Tumour Biol. 2014; 35:1565-1574.

14. Byun SS, Yeo WG, Lee SE and Lee E. Expression of survivin in renal cell carcinomas: association with pathologic features and clinical outcome. Urology. 2007; 69:34-37.

15. Parker AS, Lohse CM, Leibovich BC, Cheville JC, Sheinin $\mathrm{YM}$ and Kwon ED. Comparison of digital image analysis versus visual assessment to assess survivin expression as an independent predictor of survival for patients with clear cell renal cell carcinoma. Hum Pathol. 2008; 39:1176-1184.

16. Zamparese R, Pannone G, Santoro A, Lo Muzio L, Corsi F, Pedicillo MC, Scillitani EL, Tortorella S, Staibano S, Piscuoglio S, Lo Russo L and Bufo P. Survivin expression in renal cell carcinoma. Cancer Invest. 2008; 26:929-935.

17. Parker AS, Leibovich BC, Lohse CM, Sheinin Y, Kuntz SM, Eckel-Passow JE, Blute ML and Kwon ED. Development and evaluation of BioScore: a biomarker panel to enhance prognostic algorithms for clear cell renal cell carcinoma. Cancer. 2009; 115:2092-2103.

18. Lei Y, Geng Z, Guo-Jun W, He W and Jian-Lin Y. Prognostic significance of survivin expression in renal cell cancer and its correlation with radioresistance. Mol Cell Biochem. 2010; 344:23-31.

19. Baytekin F, Tuna B, Mungan U, Aslan G and Yorukoglu K. Significance of P-glycoprotein, p53, and survivin expression in renal cell carcinoma. Urol Oncol. 2011; 29:502-507.

20. Dornbusch J, Zacharis A, Meinhardt M, Erdmann K, Wolff I, Froehner M, Wirth MP, Zastrow S and Fuessel S. Analyses of potential predictive markers and survival data for a response to sunitinib in patients with metastatic renal cell carcinoma. PLoS One. 2013; 8:e76386.

21. Liu S, Qi L, Yu Q, Song Y, Han W, Zu X, Jiang S, Yuan J, Zeng F and Xie Y. Survivin and HLA-I expression predicts survival of patients with clear cell renal cell carcinoma. Tumour Biol. 2014; 35:8281-8288.

22. Weber T, Meinhardt M, Zastrow S, Wienke A, Erdmann K, Hofmann J, Fuessel S and Wirth MP. Stage-dependent prognostic impact of molecular signatures in clear cell renal cell carcinoma. Onco Targets Ther. 2014; 7:645-654.

23. Lu H, Cao X, Chen Q, Chen L, Chen L and Gan M. The expression and role of MEKK3 in renal clear cell carcinoma. Anat Rec (Hoboken). 2015; 298:727-734.

24. Shi ZG, Li SQ, Li ZJ, Zhu XJ, Xu P and Liu G. Expression of vimentin and survivin in clear cell renal cell carcinoma and correlation with p53. Clin Transl Oncol. 2015; 17:65-73.

25. Johnson ME and Howerth EW. Survivin: A bifunctional inhibitor of apoptosis protein. Vet Pathol.. 2004; 41:599-607.

26. Altieri DC. Validating survivin as a cancer therapeutic target. Nat Rev Cancer. 2003; 3:46-54.

27. Zaffaroni N, Pennati M and Daidone MG. Survivin as a target for new anticancer interventions. J Cell Mol Med. 2005; 9:360-372.

28. Altieri DC. The case for survivin as a regulator of microtubule dynamics and cell-death decisions. Curr Opin Cell Biol. 2006; 18:609-615.

29. Lens SM, Vader $G$ and Medema RH. The case for Survivin as mitotic regulator. Curr Opin Cell Biol. 2006; 18:616-622.

30. Yang D, Welm A and Bishop JM. Cell division and cell survival in the absence of survivin. Proc Natl Acad Sci U S A. $2004 ; 101: 15100-15105$.

31. Tran J, Master Z, Yu JL, Rak J, Dumont DJ and Kerbel $\mathrm{RS}$. A role for survivin in chemoresistance of endothelial cells mediated by VEGF. Proc Natl Acad Sci U S A. 2002; 99:4349-4354.

32. He C, Liu ZG, Ji J and Zhu HL. Prognostic value of survivin in patients with non-Hodgkin's lymphoma: a meta-analysis. Int J Clin Exp Med. 2015; 8:5847-5854.

33. Fan J, Wang L, Jiang GN, He WX and Ding JA. The role of survivin on overall survival of non-small cell lung cancer, a meta-analysis of published literatures. Lung Cancer. 2008; 61:91-96.

34. Lv SZ, Dai CX, Liu YT, Shi RR, Tang ZY, Han MZ, Bian RX, Sun BW and Wang RZ. The Impact of Survivin on Prognosis and Clinicopathology of Glioma Patients: A Systematic Meta-Analysis. Mol Neurobiol. 2015; 51:1462-1467.

35. Krieg A, Baseras B, Tomczak M, Verde PE, Stoecklein $\mathrm{NH}$ and Knoefel WT. Role of survivin as prognostic and clinicopathological marker in gastric cancer: a metaanalysis. Mol Biol Rep. 2013; 40:5501-5511.

36. Tierney JF, Stewart LA, Ghersi D, Burdett S and Sydes MR. Practical methods for incorporating summary time-to-event data into meta-analysis. Trials. 2007; 8:16. 